\title{
Gender Mainstreaming in Student Admissions in Zimbabwean State Universities: The Gap between Implementation and Ideal Practice
}

\author{
Dr. Efiritha Chauraya \\ Midlands State University, Gweru, Zimbabwe \\ Email: efirithachauraya@fastermail.com, chaurayae@msu.ac.zw \\ Prof. Tintswalo V. Manyike \\ University of South Africa, P.O.Box 392, Unisa, 0003, South Africa \\ Email: Manyitv@unisa.ac.za
}

\section{Doi:10.5901/mjss.2014.v5n8p406}

\begin{abstract}
Gender equity remains a critical issue on the agenda of higher education worldwide. In this vein the Zimbabwe National Gender Policy (ZNGP) (2000) requires all state universities to implement gender equity programmes through gender mainstreaming to ensure gender equity in the higher education system. Gender mainstreaming is aimed at establishing transformative processes and practices to benefit both women and men equally by systematically integrating policies and programmes addressing gender into all aspects of an organization's work. Thus, to mainstream gender is to move gender from the periphery to the centre focus of any activity. This paper reports on the qualitative component of an investigation of the implementation of gender policy programmes in student admissions in two selected Zimbabwe state universities. Data gathering was conducted through documentary analysis and interviews from expert informants to explore the effectiveness of gender equity in student admissions. Findings, through an appraisal of current gender policy implementation in student admissions, revealed yawning gaps between implementation obtaining in the institutions and ideal practice. The main recommendation of the study is the need for a new shift in policy program implementation, and the study outlined the main cardinal points of this new paradigm.
\end{abstract}

Keywords: gender programme, gap, beliefs, practice, gender mainstreaming, gender implementation.

\section{Introduction}

The critical nature of gender which warrants global concern has been at the forefront of the United Nations (UN) since 1975 when the first world conference on women was held (UN, 1975), UN 1996). Zimbabwe as a member of the UN shares this concern as highlighted in the UN 1998 Human Development Report on Zimbabwe which described the entire country as a "highly unequal society" in terms of gender (ZNGP, 2000). A country report, "The Nziramasanga Presidential Report on Education and Training' (1999) corroborated the previous finding by indicating that the Zimbabwean education system from primary to tertiary level is also highly unequal in terms of gender. To address this issue, a Commission of Inquiry into Education and Training was tasked: "to inquire into and report on issues of gender and gender equity with regard to access to education at all levels and the formulation of appropriates remedial measures" (Nziramasanga 1999, p.72). The Commission subsequently recommended that the government design effective policies and strategies to achieve gender equity in education. However, a study conducted by the Ministry of Higher Education and Technology (Zimbabwe) revealed that though knowledgeable about the benefits and need for gender inclusive education in policies and programmes in the country, education policy makers did not fully grasp how to develop and implement such policies and programmes (Ministry of Higher Education and Technology Policy Makers' Seminar on Gender Issues in Education in Zimbabwe 2000: 4-5). As a result, the ZNGP was developed and adopted in 2000 with primary mandate to eliminate all negative practices that impede equality and equity of the sexes through gender mainstreaming in all aspects of the development process (ZNGP, 2000).

Gender mainstreaming "seeks to produce transformative processes and practices that will concern, engage and benefit women and men equally by systematically integrating explicit attention to issues of gender into all aspects of an organization's work" (Cornwall, Harrison \& Whitehead, 2007, p. 124). The main stream is the core of the organisational activities into where other streams flow. Thus, to mainstream gender is to move gender from the periphery to the centre focus of any activity. When gender is made centre focus then it is not possible to ignore or overlook men's and women's 
issues. Gender equality is the ultimate goal of gender mainstreaming (Cornwall, Harrison \& Whitehead, 2007). Gender mainstreaming was advocated by the ZNGP to eradicate the gender inequalities in Zimbabwe universities, although the exact steps to be followed by each university were not dictated. However in terms of the success of implementation, Bunyi $(2003, p .3)$ notes that there is "little in the available literature that shows that the impact of gender interventions [in Zimbabwe higher education] are being measured or even the details of what the interventions entail and the processes through which they are being designed and implemented".

In the light of the above, this paper reports selected findings of a doctoral study that investigated the mainstreaming of gender policy programmes in student admissions in Zimbabwean state universities in response to the requirements of the government of Zimbabwe's ZNGP (Chauraya, 2011). Successful operationalisation of gender mainstreaming called for full adherence to the requirements and cardinal points of successful implementation. In this regard, the following research question was formulated: Do the implementers of gender mainstreaming in student admissions in selected universities hold values and practices in line with expectations of ideal gender mainstreaming practice? To address this question, a literature review dealing with change and the key principles of gender mainstreaming and an empirical inquiry were conducted. Based on the findings recommendations are drawn.

\section{Theoretical Perspective}

The theories and practices of management of planned behavioural change underpinned this study of gender mainstreaming (Ornstein \& Hunkins, 1993). All cornerstone models for understanding organised behavioural change hinge on the idea that change of any dimension is often confusing, threatening and creates uncertainty (Lewin, 1975). This is because those who undergo the change have their own set of beliefs, values and behaviours which may not be amenable to the change. These set of beliefs and values act as change levers that may block or support one's adjustment to the external change (Lewin, 1975). In order to install a more meaningful and long term stable change in individuals' lifestyles, these change levers should be influenced in such a way that there is compatibility of them and the desired change (Rao \& Kelleher, 2005; Ornstein \& Hunkins, 1993; Wendoh \& Wallace, 2005; Lewin, 1975). In other words, individual adaptability to the change should be pre-requisite if change has to be meaningful. This individual adaptability to the change is a process that can be achieved in various ways. However, all the change model theorists suggest that the process can best be achieved by strengthening the forces for change and weakening the forces against change (Lewin, 1975). Emphasis of the change theorists is on the need to motivate the individuals affected by the change to act based on their beliefs and values which should be made compatible with the change in the first place. If the compatibility of beliefs with change is missing, the individuals affected by the change may work under protest. Hence the emphasis is that the implementers of policy should agree with the change, or at least understand the need for change (Wendoh \& Wallace, 2005; Lewin, 1975).

Certain principles make change through the strategy of gender mainstreaming possible.

- Firstly, gender change that is being brought into the mainstreaming should be context specific. Ornstein and Hunkins (1993) advise that it is prudent to resort to policies and programmes that are context specific because such situationally-dictated programmes consider situational realities; hence they are likely to remain relevant. For a fruitful context specific policy programme, a situational analysis of the universities' gender terrains before programme implementation is imperative before design and implementation of the programme. Any gender mainstreaming should take as its starting point a through and rigorous analysis of the gender development situation rather than priori assumptions about the gender problems (Status of Women Canada, 2005). The advantage of this is allowing working from an informed point.

- Secondly, literature pointed to a need for a re-orientation of the implementers' mindsets to the gender change before gender programme implementation (Lombardo, 2003; Woodward, 2001). This 'winning of the minds and hearts' of the implementers (Wendoh and Wallace, 2005) is required to motivate all those affected by the programme, especially the programme implementers, in this case university administrators in student admissions. Seeds of change lie with these people (Wendoh \& Wallace, 2005) and approaches that ignore the processes required to change the implementers' long held beliefs and practices have little impact (Wendoh \& Wallace, 2005; Hanson, 1979; Gross, 1979). This aspect is what Lewin $(1975$, p. 12) calls "unfreezing the status quo" or what Verloo (2001, p.13) calls "strategic framing, i.e. strategic efforts of people to fashion shared understandings that legitimate and motivate action towards a goal". The Council of Europe is very explicit about the importance of this factor and in its definition of gender mainstreaming lays emphasis on 'reorganizing, re-improvement, re-development and re-evaluation of processes so that a gender equality perspective is incorporated in all programmes, and at all stages by the actors involved in gender 
mainstreaming'(Council of Europe, 1998; Lombardo, 2003). This factor is also necessary for sustainable transformation of policy programme processes to avoid incidental or accidental attention to gender. Incidental or accidental attention to gender takes place where there is a mismatch between the implementers' beliefs and their practices. It is inarguable that those beliefs have a profound influence on practices and that a lack of reorientation of these beliefs and values is likely to hinder the assimilation of the gender agenda and practices. Strategic framing or reorientation is therefore essential for the acceptance of gender policy programmes and eventually for channelling the implementation of the programmes in a certain direction.

- Thirdly, literature lays importance on the need to continuously monitor the implementation process, evaluate it formatively and summatively and review and adjust as need arises. These processes are embedded and constitutive and should remain a dialogue on the change development and progress. Literature emphasises that these processes are not optional accessories in change implementation else the relevance, effectiveness, efficiency, impact and sustainability of the change will not be gauged, ascertained and felt.

- Fourthly, the growing body of literature stresses the need for a policy which provides a framework for the entire operationalisation of the gender program (s). The policy should state what the gender programs are to do, who actually is to do it, how it is to be done and for who it is to be done. The policy, according to literature, should actually focus the gender programs such that implementation becomes very straight forward.

\section{Method}

The research question was investigated qualitatively. In pursuing the study question, endeavour was to establish a fit between institutional implementation and ideal practices regarding mainstreaming gender in students' admission.

\subsection{Site Selection and Sample}

The qualitative researcher seeks to understand a phenomenon as it occurs in its broader context. Therefore, a clear statement should be provided of how the site and persons studied were defined (McMillan \& Schumacher, 2006). Two out of the eight state universities in Zimbabwe were conveniently and purposefully sampled. This choice was mainly influenced by the quality of the selected university's gender equality programmes as determined in a preliminary study. Heeding Neuman (2003)'s caution that the researcher should protect the rights and welfare of the communities researched, anonymity of these universities was ensured by giving the two sampled sites the pseudonyms, Blackwell and Stoneville University respectively. Blackwell University was established in 2000 and has seven academic faculties with seven deans and 33 chairpersons. The institution was explicit about its commitment to gender equity and equality in its recruitment policies. In 2006, the institution developed an institutional gender policy, claiming to "ensure that the National Gender Policy cascades down to institutional levels, which process ensures operationalisation of the policy through identified programs and activities" (Blackwell Gender Policy, 2006,p.2). Henceforth, the policy articulated strategies designed to close gender gaps in admission procedures. Stoneville University was established in 2002 and had five academic faculties with twenty chairpersons. Although it had no documents that dealt with gender per se, the Office of Information verbally emphasized the institution's commitment to gender equality in its recruitment and admission practices. This institution was guided in its operations by its Strategic Plan 2008 -2013. Furthermore, student admission into higher education in Zimbabwe is not administered by a centralised unit. As is the case with all other universities in the country, the selected institutions had their own unique set of criteria for selecting candidates for admission and in both students were not just admitted to university as a whole, but to a particular field of study.

Within these two sites, twenty-one (21) participants were purposively sampled in a quest for "information-rich participants" (Neuman, 2003, p. 200), that is, those administrators responsible for the implementation of gender policy programmes in student admissions. The sample consisted of two deputy registrars (one from each institution), two senior assistant registrars (one from each institution), five deans of academic faculties (three from Blackwell and two from Stoneville) and twelve departmental chairpersons (seven from Blackwell and five from Stoneville).

\subsection{Data Gathering and Analysis}

Semi-structured individual interviews were used to explore implementation of the selection practices and procedures in student admissions using an interview guides consisting of both closed and open questions. Closed ended questions were included to gather the interviewees' views and because they allowed for a quicker categorization of responses (Robson, 1997). Open ended questions by their nature develop trust, were perceived as less threatening and allowed an 
unrestricted or free response (Robson, 1997). Interviews were audio taped to have complete and accurate data (Maxwell, 1996; Lofland, 1971), except where it was not in the interest of the interviewee. All questions asked centred on answering the research question cited in the introduction. The interviews at both sites were carried out in the offices of the respondents. All the interviewees had offices of their own by virtue of their positions at the institutions. These familiar settings enabled the participants to talk freely about their concerns of gender policy programmes in a relaxed environment. However, certain participants only consented to give certain information when they were not recorded. Further six chairpersons (three at BU and three at SU) made non-audio recording a condition for the interview. Observing the ethics of research that protect participants' rights meant that the requirements of the participants were upheld and in these cases substantial notes were made during interviews.

Analysis of the data for this article was undertaken according to Strauss and Corbin (1998) stages of qualitative data analysis. First, a verbatim manual transcription of each recorded interview was produced. Data that was not recorded was typed and edited. Secondly, contextual coding (McMillan \& Schumacher, 2006) took place which involved reading the data and identifying frames of analysis. The latter are levels of specificity within which data was examined. This process segmented data and each segment was labelled with a code. The third stage involved generating key groupings/categories through the coding. 'Fine grained analysis' (Maxwell, 1996, p.45) constituted the fourth stage: grouping the relationships between categories and trends into broad themes consistent with the identified research question. Finally, from these themes, conclusions were drawn.

\section{Research Findings}

Seven major categories emerged from the analysis of the participants' responses. Findings per each of the seven are presented and analysed below. Descriptions of the implementation are supported by evidence mostly in form of quotations from the interview transcripts (Ely, Vinz, Downing \& Anzul, 1997).

\subsection{Bases of Current Gender Policy Implementation in Student Admissions}

The first task was to ascertain the origin of the gender changes being implemented in student admissions since the studied literature had averred that change has to be context specific. Administration at both institutions said that it was government directive through the ZNGP of 2000. However the ZNGP was hailed and commended for allowing each university to devise and implement its own policies and strategies. This certainly was a move towards institutionally drawn gender initiatives since experience has shown that gender issues differ by institution. Probing further on this issue, it emerged that, the studied institutions did not thoroughly make individual institutional analyses, but went straight into implementation, guided mainly by what universities like Makerere who were long in the game were doing. Thus the study registered its first score on the gap between the implementation and ideal practice since much against ideal practice; it would appear the institutions worked from assumptions

Like situations obtaining in universities that were long in the game, the findings revealed three types of gender initiatives being implemented in student admissions. These were: lowering of entry points, the bridging programme and quota reservations.

Both institutions implemented lowering of entry points for the disadvantaged sex group determined according to the context of the respective faculty and its offerings. Bunyi (2003) terms lowering entry points as 'awarding bonus points' and reports that it is a common practice in most African universities. At the studied institutions, lower entry points were common in the Faculties of Social Sciences and of Commerce, while higher entry points were established in the Faculties of Natural Sciences and of Natural Resources. This practice advantaged only female students; it failed to advantage male students even in departments where they formed the minority, such as, the Department of Food Science and Nutrition at $\mathrm{BU}$ and the Department of Early Childhood Education at SU. The practice reflected a difference of opinion between the implementers of policy in student admissions and ideal gender practice. Ideal gender practice recognises that there are both males and females at risk, and so it should be a question of ensuring equitable treatment.

The bridging programme was implemented at $\mathrm{BU}$ and was under consideration for implementation by some departments at SU. Although the BU gender policy specified that the practice was only for increasing female student representation in the Faculty of Natural Sciences, the practice was normal practice in other departments, especially the Faculty of Commerce and Natural Resources. The bridging period at this university comprised one semester to bridge the articulation gap between university and high school for those students who met the mean grade criterion for admission into university but did not meet the faculty requirement for degrees in any of the faculty departments. This practice concurred with practice in higher education in Eriteria (Bunyi, 2003) and Tanzania's University of Dar es Salam (Masanja, 
2001).

The quota system was implemented in very few departments at SU and in a number of departments at BU. Invariably, in almost all the departments that practised it, quotas were set to increase female participation rates in departments that were traditionally male dominated and not vice versa. When probed on how participants viewed the gender sensitivity of the programme, most found the practice crude. As one participant described it as: "Unnecessary unfairness in the selection process...it's more or less saying lower points for females because to fill the female quota you have to go down to unrealistic points compared to the male quota.".

\subsection{Policy on Student Admissions}

The BU had a written gender policy and the SU followed verbal pronouncements by the Vice Chancellor that acted as policy directive. However, neither institution had a stand-alone gender policy on student selection. At SU it was part of the institutional strategic planning process; at BU the student admissions policy was part of the general academic regulations of the university. The student selection criteria were also alluded to in the university act and referred to in the institutional gender policy. However, these documents disclosed nothing on the mechanics of student selection. Only the BU gender policy cited inclusion of programmes of affirmative action to achieve a critical mass of women but it did not elaborate how this was to be achieved other than the bridging programme. The documents mentioned the personnel involved and advocated transparency within the practice. However, the documents were silent on how the selection had to be done and how the transparency was to be attained and maintained. The deputy registrars and the deans of academic faculties said they had read the referred to documents but none knew what these documents stipulated about student enrolment save only the minimum entry qualifications.

The lack of a stand-alone policy is lamented by ideal practice as its absence makes implementation haphazard. The importance of a policy cannot therefore be over emphasized. Its absence was a lack in the institutional road to gender equality and a big gap between implementation and ideal practice.

\subsection{The Mechanics of Student Selection.}

In both institutions, student selection was done by a selection committee comprised by deans (who could be members) and departmental chairpersons. The deans' main duty was to supervise or chair the selection committee meetings. Almost all the responses indicated this practice as a good measure of transparency. Most selection committees were headed by men, which gave the exercise a predominantly male face and conveyed patriarchy as the predominant culture of the selection process.

\subsection{The targets}

Institutional targets regarding enrolment at both institutions were not sex disaggregated. Drawing on Murison (2004)'s work on the need for sex disaggregated data in any development scheme that strives to achieve gender equality, this study found the lack of such in the institutional targets limiting the actors in identifying the real and potential contributions of the gender policy programmes for female and male students. This absence of sex disaggregated data made monitoring and evaluation of the outcomes of the gender policy programmes by sex impossible. What was alluded to by the deputy registrars especially was a drive towards gross gender parity. But studies have already revealed that such a practice hides gross gender inequalities (Unterhalter, 2004). The benefits of gender policy programmes are inadequate if they do not differentiate outcomes for males and females.

The target of the mainstreaming efforts was 'the female student', yet ideal gender mainstreaming target is gender equality in its broad context. The main change object of the policy programmes should be "systems and structures themselves - those much institutionalized practices that cause both individual and group disadvantages in the first place" (Verloo, 2001, p. 3). Thus on this score again, the findings revealed a contradiction between implementation and ideal practice as propounded by Lombardo (2003); Jahan (1995); Walby (2005) and True (2001). These authors caution that equality is not, and should not be, a feminist agenda, and as such programmes and activities should be targeted at gender not feminism.

\subsection{Monitoring, Evaluation, and Reviewing of Policy Implementation}

This theme discusses the monitoring, evaluation and reviewing of policy programme practices by the actors in student 
admissions. Actors in most cases said they reviewed their practices; very few out rightly said they did not monitor, evaluate or review their practices. However, a scrutiny of the monitoring process revealed that such monitoring, evaluation and reviews were not vigorous. What most termed monitoring and evaluation was checking whether the admitted students held the reuisite ' $A$ ' level subjects and that the admission list was not tampered with. This was primarily done by the deans and in all faculties and departments there was no written record. However, as Murison (2004) and Hannan (2008) reiterate, monitoring should be an ongoing practice to check whether the actors in student admissions are on track. Evaluations should help the actors in student admission determine what difference(s) their efforts were bringing about. Drawing on this information, monitoring and evaluation should enrich accountability and transparency of the practices and enable specific departments and faculties to undertake self-assessment of selection practices. The established lack of formal gender monitoring, evaluations and reviews incapacitated the actors in student admissions, in particular the Selection/Faculty Planning Committee to extract relevant information from past and ongoing programmes that can subsequently be used as basis for fine-tuning programmes. The lack of a rigorous gender evaluation was also undoubtedly a reason that kept the gender equality mandate under siege in student admissions at the institutions and was a yawning deviation from ideal practice.

\subsection{Gender Sensitivity of Implementers in Student Admissions}

Gender awareness implies the recognition that men and women have different needs which must be recognized and therefore realities for men and women in society are not the same. Gender sensitivity is a step ahead of gender awareness. It is the translation of awareness into practice, which results in changes in perceptions (Revees \& Baden, 2000). Most actors in student admissions had not received any gender awareness education or any gender sensitivity training, beside the registrars, deputy registrars and deans of academic faculties of BU who attended a day's workshop on gender in 2007. However, a one-day workshop is inadequate to change attitudes and perceptions. The male chairpersons at SU said that gender workshops at their institution gave the impression that gender sensitivity or awareness education was for only women. One of them commented: All I know is that when these people talking about gender come to the institution, it is through student affairs. They assemble and talk to female students and some volunteers from the women's board within this institution. I haven't seen any men around attending these."

The consequence of excluding men from these meetings gave rise to hostilities between men and women at grassroots level. Regarding the exclusion of men from the meetings, a woman participant mentioned that after the workshop, the men teased and laughed at the women delegates. When the participant asked for a lift at the close of the workshop, a male colleague replied: "We are gender, gender in here all of us. Look for your own car that is not gender and just like that they left me behind".

Probing and further probing revealed that gender knowledge was derived from talks on gender in the media, in their VCs' speeches at graduation ceremonies, important functions and addresses to the Senate, a body of which all chairpersons are members. The chairperson of the Gender Committee at SU cited lack of resources as the main challenge. This finding contradicted the requirements of mainstreaming as a gender equality perspective within an institution. Woodward (2001, p.134) maintains that mainstreaming a gender equality perspective implies that the "various policy fields should be infiltrated with gender sensitivity" and it is this sensitivity that enables them to operate in a gender sensitive way.

Commenting on gender sensitivity, a chairperson said: In this department we are very sensitive. We consider points and males are the ones who are intelligent." A senior assistant registrar said: "Girls saturate Arts and Social Sciences departments but have no interest in Sciences". Another chairperson responded: "The problem we have is that in Zimbabwe girls don't like education, let alone university education, as men do, so much so that even if we bridge them we have less of them". Sentiments like this show a lack of rigorous engagement in gender and gender analysis of the Zimbabwe education system and culture and the impact on boys' and girls' educational access and attainment. In the absence of a sound engagement in gender education, these actors operated from their own institutions' organisational ethos. Internalizing gender concepts in a meaningful way would help the actors in student admissions to understand the spectrum of differences between male and female students and they may then systematically address the gender gaps in student selection. This would thus make it possible for the actors in student admissions to plan in a manner that would ensure that both male and female students equitably benefit from the student enrolment practice. Gender awareness and sensitivity in itself sensitizes the actors in student admission to the existence of prejudice with respect to responses such as, "females are not intelligent." Such reactions are the result of gender stereotyping which can only be countered by extensive deconstruction through engagement in gender awareness and sensitivity training. Thus while the ideal emphasises gender awareness of implementers, the situation obtaining was on the contrary. 


\subsection{Perceptions of Problems and Prospects for Gender Equality in Student Admissions}

Direct questions were asked on perceived challenges faced in the implementation of gender equality in student admissions. Most actors particularly lamented the absence of a stand-alone policy on student selection for the universities or particular faculties as much of the operational inconsistencies in student admissions were due to lack of a written guide. The lowering of entry points and quota reservations, although stated as a matter of policy by the deputy registrars, was at the discretion of a particular selecting committee. Only the bridging programme at one institution was consistently implemented. Most actors felt that doing away with the gender programmes and selecting students according to the strict point system would improve the situation in student admissions. One chair cited the consistency a point system affords: "Because if it's a minimum of 10 points, it's a minimum of ten points. No other measure could achieve such consistence and what other fairness would you want".

The participants proffered a few suggestions for improvements. The need for a stand alone policy on student admissions was stressed by many participants, chairpersons and deans of faculties,especially. A chair expressed the difficulty of operating under verbal instructions: "Which sometimes you get through someone because you didn't attend the senate meeting. With a policy what you are required to do will be there in front of you. It makes you understand your responsibility easier". The deans of faculties felt that a policy would lessen their burden: "Because I don't have to check all the time. You see, a policy guides lecturers' operations with minimal intervention by me". Further, most participants recommended gender sensitisation for all members of the university community. A chair felt that this would win greater understanding for current policies in admissions "so that when they [other staff] see us not taking their male candidates they will not frown on us".

\section{Conclusion}

The study has highlighted a number of factors that gave rise to the gap between ideal practice and implementation of gender policy programs in student admissions in Zimbabwe State Universities. The main factors identified were: initial failure to make a situational analysis and take care of the beliefs of the implementers, lack of re-orientation of the implementers' mind-sets to suit the gender agenda, a lack of gender awareness training to provide implementers with correct visions of gender mainstreaming and absence of a standing policy to ensure proper articulation and implementation guidelines. In view of these findings, promising initiatives to narrow or close the gap are recommended. The following recommendation is made:

- A more strategic approach which among other things starts from a situational gender analysis before program designing and implementation and that vigorously attempts to re-orient the implementers' beliefs, values, attitudes and aspirations towards a gender agenda be pursued. To achieve this, the institutions should mount extensive (to cover not only the university administrators, but the entire university community) and intensive (routine workshops) gender consciousness- raising workshops. The gender conservatism of the actors (that was revealed in the findings) can only be permeated by a substantial engagement in gender through a continuous incrementalist attendance of suitable workshops. Gender is inside, (beliefs, attitudes, perceptions and values) hence the need to sensitise actors to gender in student admissions from the inside out. Thus, then, it is the beliefs, attitudes, perceptions and values of the constituency which should be made pro gender first and be kept pro gender throughout program implementation. The study further recommends adoption of the following implementation model (fig 1.1) for sustainable and strategic reduction of gaps between implementers' beliefs and practices through increased gender- consciousness raising of the constituency. 
Figure 1.1: The proposed model: A sustainable and strategic plan to reduce gender inequality in student admissions in universities.

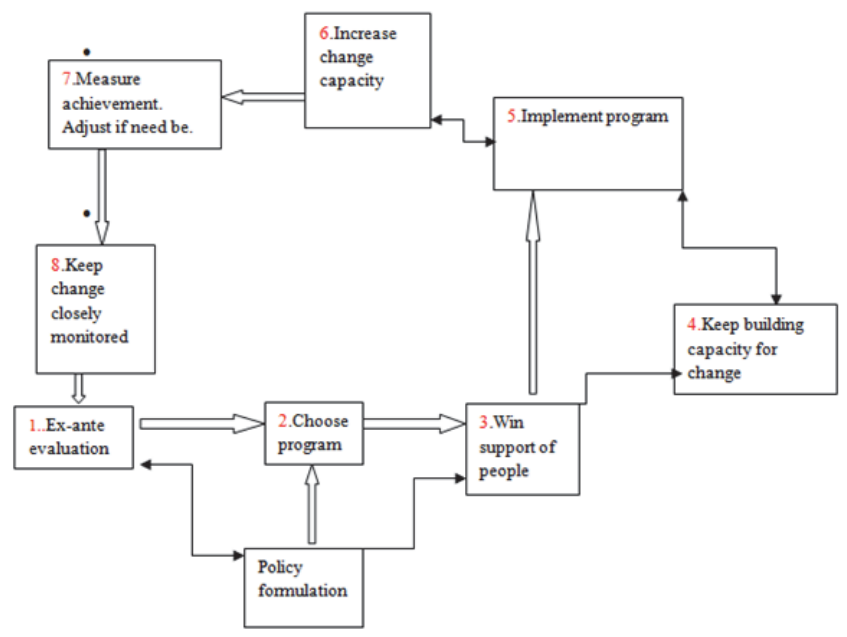

The model, (it is felt), reduces vulnerabilities and at the same time increases capabilities for closure of gaps and this is why its levels $3,4,6$, and 8 are on capacity building for sustainable change. The implementers' hearts should be kept won throughout programme implementation. Only then can university policy makers pave a path towards a more gender responsive team of implementers whose theoretical orientation is reflective of current and pertinent research in the field of gender equality implementation - i.e. a team whose gender beliefs match their practices and whose practices are congruent to the expectations of the strategy of gender mainstreaming and attainment of the goal of gender equality. "Paths are made by walking". (Hellum et al, 2007, p. 39)

\section{References}

Bunyi, G. (2003). Interventions That Increase Enrolment of Women in African Tertiary Institutions. Retrieved from http://www.Unesdoc.unesco.org/images/0015/001510/15105.

Chauraya, E. (2011). The Implementation of Gender Policy Programmes in Selected Universities in Zimbabwe. Doctoral thesis, University of South Africa.

Cornwall, H., Harrison, E., \& Whitehead, A. (Eds). (2007). Feminism in Development. London: Zed Book Ltd.

Council of Europe. (1998). Gender Mainstreaming: Conceptual Framework, Methodology and Presentation of Good Practices. Brussels: Council of Europe.

Ely, M., Vinz, R., Downing, M., \& Anzul, M. (1997). On writing qualitative research: Living by words. London: Falmer Press.

Gross, N. (1979). The Dynamics of Planned Educational Change. Berkeley, California: McCutchan.

Hannan, C. (2008). UN Gender Mainstreaming Strategy: Achievements and Challenges. Retrieved from http:/www.un.org/women watch/news/speech2008/Korea.

Hellum, A., Steward, J., Ali, S., \& Tsanga, A. (2007). Human Rights, Plural legalities and Gendered Realities: Paths are made by walking. Harare: Southern \& Eastern African Regional Centre for Women's Law (SEARCWL) with Weaver Press.

Jahan, R. (1995). The Elusive Agenda: Mainstreaming Women in Development. London: Zed Books.

Lewin, K. (1975). Force Field Theory in Social Science: Selected Theoretical Papers. Westport,CT: Greenwood Press.

Lofland, J. (1971). Analyzing social settings. Belmont, Ca: Wadsworth Publishing Company.

Lombardo, E. (2003). "Integrating or Setting the Agenda? Gender Mainstreaming in the two European Conventions on the Future of EU and the Charter of Fundamental Rights.Unpublished Paper for ECPR Conference, Marburg, 18-21 September 2003. Retrived from www.unizar.es/union_europea/files/Lombardo_GVConv.pdf.

Masanja, V. (2001). Structural Changes and Equal Opportunities for All: a case study of the University of Dar es Salaam. A paper commissioned by FAWE and presented at the $10^{\text {th }}$ General Conference of the Association of African Universities (AAU). Nairobi.

Maxwell, J. A. (1996). Qualitative research design: An interactive approach. Thousand Oaks: Sage Publications.

McMillan, J., \& Schumacher, S. (2006). Research in Education: Evidence-based inquiry. New York: Pearson Education.

Ministry of Higher Education and Technology. 2000. "A Report on the Policy Makers Seminar on Gender Issues in Education in Zimbabwe." A workshop report developed for UNICEF Zimbabwe, 26-29 September 2000, Kadoma, Zimbabwe.

Murison, S. (2004). Elements of gender mainstreaming strategy: A fourteen point framework. Retrieved from 
http://www.capacitydevelopment.net/documents/elements/Gender Mainstreaming.

Neuman, W. L. (2003). Social Research Methods: Quantitative and Qualitative Approaches. Boston: Allyn \& Bacon

Nziramasanga Commission. (1999). Report of the Presidential Commission of Inquiry into Education and Training in Zimbabwe.

Government Printers: Harare.

Ornstein, A., \& Hunkins, F. (1993). Curriculum foundations principles and theory. Boston: Allyn and Bacon.

Rao, A., \& Kelleher, D. (2005). "Is there life after gender mainstreaming?" Gender and Development, 13(2), 57-69.

Reeves, H. \& Baden, S. (2000). Gender and Development: Concepts and Definitions, Bridge Report No. 55. Retrieved from http://www.ids ac uk/bridge.

Republic of Zimbabwe. (2000). The National Gender Policy (Zimbabwe) 2000. Harare: Gender Development in the Ministry of Youth Development, Gender and Employment Creation. www.genderlinks.org.zw/article/the_national_gender_policy_zimbabwe /publications.

Robson, C. (1997). Real World Research: A resource for social scientists and practitioners-researchers. Oxford: Oxford.

Status of Women Canada. (2005). Gender based analysis: a guide for policy making. Retrieved from http://www.swc-cfc.gc.ca

Strauss, A., \& Corbin, J. (1998). Basics of Qualitative Research: Techniques and procedures for developing grounded theory. Thousand Oaks: Sage Publications.

True, J. (2001). Transnational Feminist Networks and Gender Mainstreaming: A Comparative Analysis presented at the American Political Science Association, Atlanta, Georgia,2-5 September 2001.

United Nations. (1975). "First World Conference on Women". New York: UN. Retrieved from

www.choike.org/nuevo_eng/informes/1454.htm/catded .

United Nations. (1996). "Beijing Declaration and Platform of Action". New York: United Nations. Retrieved from www.un.org/womenwatch/daw/beijing/platfrom/plat/htm.

Unterhalter, E. (2004). Gender equality and education in South Africa: Measurements, scores and strategies. Paper delivered at British Council HSRC conference, Gender Equity in Education. Cape Town. Retrieved from www.uvh.nl/.../Publications\%20 Elaine\%20 Unterhalter.doc.

Verloo, M. (2001). "Another Velvet Revolution? Gender mainstreaming and the politics of implementation". Retrieved from www.citeseerx.ist.psu.edu/viewdoc/download?do=10.1.1.114

Walby, S. (2005). Gender Mainstreaming: Productive tensions in theory and practice. Social Politics, 12, 321-343.

Wendoh, S., \& Wallace, T. (2005). "Rethinking Gender Mainstreaming in African NGOs and Communities." Gender and Development, 13(2), 70-79.

Woodward, A. (2001). Gender Mainstreaming in European Policy: Innovation or Deception. Discussion Paper. Berlin: WZB-Berlin. 